\title{
Aesthetics in Periodontal Therapy!
}

\author{
Dr. Grishmi Niswade ${ }^{1}$, Dr. Salman Ansari ${ }^{2}$ \\ ${ }^{1}$ Lecturer, Department of Periodontology, Swargiya Dadasaheb Kalmegh Smruti Dental College and \\ Hospital, Nagpur, Maharashtra, India \\ ${ }^{2}$ Reader, Department of Periodontology, Swargiya Dadasaheb Kalmegh Smruti Dental College and Hospital, \\ Nagpur, Maharashtra, India
}

\section{ABSTRACT}

Aesthetics is an inseparable part of today's dental treatment, the demands of which are continually increasing. The ultimate goal of periodontal therapy is to provide an aesthetic, functional, periodontally healthy and easily maintainable dentition to the patient. It needs to be emphasized that complete and accurate diagnosis is essential to provide an effective aesthetic periodontal therapy which often requires a multidisciplinary approach for complete treatment. Other prerequisites fora good aesthetic outcome apart from correct diagnosis include thorough attention to detail, development of a comprehensive treatment plan and effective implementation of the advanced techniques and materials.

Keywords : Aesthetic Periodontal Therapy, Dental Treatment, Cementoenamel Junction, Mucogingival Complex, Gingival Tissue, Gingival Recession, Gingival Hyperpigmentation, Gummy Smile, Socket Preservation, Microsurgery, Minimally Invasive Surgical Technique, Pilla Preservation Flap

\section{INTRODUCTION}

Dental treatment to a point that is less acceptable than optimal aesthetics is no longer accepted by the patients. Providing a perfect blend of optimum aesthetics and correct treatment for the patient is often a challenge to the clinician. Periodontal plastic and soft tissue reconstruction surgeries are the periodontal procedures providing aesthetics. ${ }^{1}$ Modern dentistry provides with newer materials and techniques which focus on maximal safety and minimal discomfort. ${ }^{2}$

The gingiva, teeth and lips form an integral part of an aesthetic smile. ${ }^{3,4} \mathrm{~A}$ proper form and structure of all the three result in optimal aesthetics. The shade, alignment in the arch and shape of the tooth are essential. With the advent of newer materials in endodontic dentistry an, fast and accurate corrections can be made in the structure of the tooth. ${ }^{5}$ The position of the gingival margin should be ideally 1 $\mathrm{mm}$ above the cementoenamel junction. This is ensured by periodontal therapy. The lip lines that relate to the mucogingival complex can be classified as high, medium and low depending upon the exposure of gingival tissue. ${ }^{6}$

The horizontal and vertical reference lines of the face include the pupillary line passing through both the pupils of the eye, line crossing the midline of the pupils to the corner of the mouth and gingival line which is a line running through the height of contours of the maxillary anterior teeth. The pupillary line should be parallel to the gingival line and the interndental papilla between the maxillary 
central incisors should coincide with the midline of the face. ${ }^{7}$

\section{Indications of aesthetic treatment in dentistry}

Gingival recession- It is defined as apical shift of the gingival margin tissue from the cementoenamel junction with exposure of root surface to the oral cavity. It is usually associated with hypersensitivity, root caries and abrasion. Various etiological factors are responsible for gingival recession that includes anatomical factors such as fenestration and dehiscence of alveolar bone, abnormal tooth position in the arch, aberrant path of tooth eruption, abnormal shape of the tooth, physiologic factors such as orthodontic tooth movement, factitious habits of the patient, pathological factors such as improper tooth brushing and flossing techniques, intraoral piercing, malocclusion, denture or restorative therapy, plaque and calculus etc. ${ }^{8}$ Several techniques have been used to cover denuded roots such as free soft tissue procedures that include free gingival graft, connective tissue graft and pedicle soft tissue grafts such as rotational flap procedures, advanced flap procedures or regenerative procedures. Gingival mask or gingival veneers made from acrylic resin or flexible silicon can be used for root coverage in patients not willing for surgery or as interim measures when treatment is delayed due to certain reasons. They mask the unsightly appearance of receded gingival margins and lost interdental papilla which may make the patient conscious. ${ }^{9}$

High frenal attachment and midline diastema- A frenum is a mucous membrane fold that comprises of muscle and connective tissue fibres. ${ }^{10,11}$ A high frenal attachment that is an attachment closer to the gingival margin which creates a pull on the gingival crevice and makes it difficult for the individual to maintain oral hygiene in that area. Frenal attachments have been classified as mucosal, gingival, papillary and papilla penetrating based on their location of attachment. ${ }^{12}$ Sometimes a high frenal attachment is present along with inadequate width of attached gingiva and shallow vestibule thus making oral hygiene procedures a herculean task for the patient. Surgical procedures to correct frenal attachments are frenotomy and frenectomy which can be performed with other procedures such as augmentation of attached gingiva and vestibuloplasty.

Gingival hyperpigmentation- Increased melanin pigmentation of gingiva is an aesthetic concern among individuals. ${ }^{13}$ Gingival depigmentation is a periodontal plastic procedure that is used to remove gingival hyperpigmentation by various techniques such as scalpel, electrosurgery, cryosurgery, free gingival graft, alloderm and abrasion with diamond bur.

Gummy smile- A gummy smile can be caused by altered passive eruption or vertical maxillary excess. A gummy smile along with gingival hyperpigmentation is often present due to which the patients become aesthetically conscious while smiling. ${ }^{13}$ Lip repositioning is the surgical procedure used to correct the gummy smile by correcting the position of the lip line.

Black triangle of loss of interdental papillaInterdental papilla is that part of gingiva that occupies the embrasure beneath the contact point of two adjacent teeth. ${ }^{14}$ The shape of the interdental papilla is determined by the contact relationships between the teeth, width of tooth surfaces and course of cementoenamel junction. Its presence or absence is of great concern to periodontists, restorative dentists and to the patients. The loss of inter proximal papilla which often results because of periodontal disease (plaque associated), traumatic oral hygiene procedures, abnormal tooth shape, improper contours of restoration, spacing between teeth or orthodontic tooth movement, can lead to aesthetic or cosmetic deformities which is also known as "Black triangle". ${ }^{15}$ 
Its reconstruction is one of the most challenging and least predictable procedure. Treatment includes correction of traumatic oral hygiene procedures, correction of prosthesis or restorations, orthodontic closure of space between the teeth and repeated curettage of papilla. Surgical techniques include the use of pedicle flap, semilunar coronally repositioned flap, envelope flap, autogenous osseous and connective tissue grafts and microsurgery.

In adequate crown height and margin placement of restorations in the maxillary anterior area- Short clinical crown height can result from deep subgingival caries, tooth fracture, iatrogenic factors etc. Surgical crown lengthening is a procedure to increase the clinical crown length without encroaching upon the biologic width. ${ }^{16}$ Techniques used for crown lengthening include gingivectomy, apically repositioned flap with or without osseous surgery and forced orthodontic eruption with or without fibrotomy. ${ }^{17}$ The factors that decide which procedure is to be used are width of attached gingiva, area of surgery such as aesthetic area (maxillary anterior region), crown to root ratio, proximity of roots, anatomical morphology of roots, location of furcation and individual tooth position.

Gingival defects due to gingival or periodontal disease such as interdental craters, alteration in the physiologic contour of gingiva-Gingival soft tissue deformities where physiologic contour of gingiva is altered include gingival craters and clefts, gingival enlargement and interdental crater resulting from necrotizing ulcerative periodontitis. Gingivoplasty is a procedure by which gingiva is reshaped to correct deformities. ${ }^{18}$ It is similar to gingivectomy but the objective of surgery is different. The procedure can be performed with scalpel, laser or electrosurgical unit.

Inadequate ridge height or width of the alveolar crest for placement of prosthesis in a missing tooth or teeth-
Dental implant is a reliable option for treatment of missing tooth or teeth. However, in aesthetic areas such as the maxillary anterior region, deficient alveolar crest can lead to compromised dental prosthesis including removable and fixed partial dentures, adverse angulations, mechanical overload and aesthetic discontent. The deficiency in the alveolar ridge may result from tooth loss due to extraction, advanced periodontal disease or trauma, chronic use of removable appliances, dehiscence or fenestration defects, congenitally missing teeth and odontogenic cysts or tumours. Thus augmentation of bone becomes a necessity in such cases. Methods for ridge augmentation include particulate and block grafting, guided bone regeneration with or without growth and differentiation factors, ridge splitting, expansion and distraction osteogenesis. ${ }^{19}$

Exposure of impacted canine for placement of orthodontics band- Impacted tooth is the one that fails to erupt or erupts partially. After third molars, canines are the most commonly impacted teeth. ${ }^{20}$ Palatal impactions are more common than labial impactions. ${ }^{21}$ If treatment is not done, then canine impactions can lead to labial or lingual eruption of nearby teeth, loss of arch length, internal or external root resorption, dentigerous cyst formation and possible infection. ${ }^{22}$ Surgical exposure of the impacted tooth is carried out to bring the tooth in proper occlusion.

Socket preservation- Resorption of alveolar bone is a common clinical problem which can be a physiologic process or a pathologic process. There are morphological alterations in the alveolar bone after extraction ${ }^{23}$, both vertically and in width of residual bone along with changes in the buccal alveolar bone plate. More the time period after extraction exceeds more is the resorption rate which is highest during the first six months of extraction. This ridge deformity causes functional and aesthetic problems in rehabilitation of the edentulous area. Socket 
preservation techniques using various materials are being performed to preserve the extraction socket. ${ }^{24,25}$

Preprosthetic surgeries- These surgeries include procedures that are used to modify and correct the morphology of oral structures to facilitate retention of prosthesis and improve its prognosis in the long term. ${ }^{26}$ These procedures consist of surgeries to correct the morphology of alveolar bone such as alveoloplasty, removal of exostosis, tori, undercuts, genial tubercles and tuberosity reduction and vestibuloplasty.

\section{Surgical considerations to preserve aesthetics-}

\section{Minimally invasive surgical technique (MIST)-} Cortellini and Tonetti in 2007 proposed minimally invasive surgical technique (MIST) which was later introduced as modified MIST (M-MIST). 27 This technique makes use of papilla preservation flaps. MIST involves complete access to the interdental areas by elevation of interdental tissues whereas $\mathrm{M}$ MIST involves gaining access to the interdental defect through elevation of a small buccal flap without elevation of the interdental papilla. This technique helps in gentle handling of periodontal soft and hard tissues, avoiding trauma and minimizing recession of the tissues.

Papilla preservation flap- It is a type of flap procedure that aims to obtain primary closure of flap and preservation of interdental tissue. It maintains an aesthetic value and is a suitable option for regenerative procedures in the interdental areas. Gingival recession and interdental spacing following healing after periodontal surgery is not desirable in aesthetic areas such as maxillary anterior region. This type of flap is suggested by various authors such as Takei e tal in $1985^{28}$ suggested Conventional papilla preservation flap, Cortellini et al $1995^{29}$ suggested Modified papilla preservation flap and simplified papilla preservation flap. Bianchi and Basseti in
$2009^{30}$ suggested a Whale's tail technique to preserve interdental tissue in guided tissue regeneration technique.

Single flap approach (SFA)-Trombell L et al 2009 suggested a Single flap approach to preserve the integrity of periodontal tissues in cases where the extent of osseous defect is limited to either buccal or lingual side. ${ }^{31,32}$ Therefore only one side of the flap is elevated and the opposite side is left intact. Post operative gingival recession is minimal in this technique and is therefore preferred in aesthetic areas.

Microsurgery - Periodontal microsurgery is a refinement of basic surgical techniques made possible by the improvement in visual acuity gained with the use of a surgical microscope. Tissue trauma and bleeding can be minimized and an aesthetic surgery can be performed with the use of microsurgical instruments because of intricate detail and small scale work made possible by surgical microscope. This technique involves the use of microsurgical instruments which are manufactured under high magnification and magnification systems including two types of magnification loupes compound loupes and prism loupes and an operating microscope. ${ }^{33}$

\section{IV.CONCLUSION}

In this day and age, patients are becoming more aware aesthetically and aesthetic considerations are becoming more relevant in dental treatment planning. However, such patients should be explained that aesthetics is not all about having 'pretty teeth', an aesthetic smile is a harmonious relationship between teeth, lips and gingiva and that consideration has to be given equally to all three components. Providing aesthetics uses a multidisciplinary approachincluding restorative dentistry, prosthodontics, orthodontics and periodontology.However, a sound periodontal health is the founding stone for further aesthetic reconstruction of the oral cavity. 


\section{REFERENCES}

[1]. Shankar Babu, KhushbuAdhikari. Periodontal approach to estheticdentistryPakistan Oral \& Dental Journal Vol 35, No. 1 (March 2015)

[2]. Bennani $\mathrm{V}$ et al. The periodontal restorative interface: esthetic considerations. Periodontology 2000, Vol. 74, 2017, 74-101

[3]. David h. Wong, Jerome Cha, 2007. "A periodontal-restorative approach to achieving an esthetic outcome in worn dentition". Contemporary esthetics: 11; 24-29.

[4]. David. A. Garber, Maurice.A.Salama. "The aesthetic smile: diagnosis and treatment". Periodontology 2000, Vol. 11, 1996, 18-28.

[5]. Padmanabhan S, Reddy VA. "Inter-disciplinary management of a patient with severely attrited teeth". J Indian SocPeriodontol 2010 Jul; 14 (3): 190-94.

[6]. Hsu BS. "Comparisons of the five analytic referencelines of the horizontal lip position: their consistency and sensitivity". Am J OrthodDentofacialOrthop. 1993 Oct; 104(4): 355-60.

[7]. Lee RL. "Standardized head position and reference planes for dento-facial aesthetics". Dent Today 2000; 19: 82-87.

[8]. Zucchelli G et all. Periodontal plastic surgery. Periodontology 2000, Vol. 68, 2015, 333-368

[9]. VidyaDodwad ,NandniNayyarHinaBedi, Perio Aesthetic Rejvenation. Indian J Stomatol 2012;3(2) :125-28

[10]. Fowler EB, Breault LG. "Early creeping attachment after frenec+tomy: a case report". Gen Dent. 2000 Sep Oct; 48(5): 591-93.

[11]. Peacock ME "Frenotomy and keratinized tissue augmentation". Gen Dent. 1998 Mar-Apr; 46(2): 194-96.
[12]. Placek M, Skach M, Mrklas L. "Significance of the labial frenum attachment in periodontal disease in man. Part I. Classification and epidemiology of the labial frenum attachment". J Periodontol 1974; 45: 891-94.

[13]. Surgical esthetic correction for gingival pigmentation: Case series. Journal of Interdisciplinary Dentistry / Sep-Dec 2012 / Vol-2 / Issue-3

[14]. Cohen B. "Morphological factors in the pathogenesis of periodontal disease". Br Dent J 1959; 107: 31

[15]. Sharma AA, Park JH. "Esthetic considerations in interdental papilla: remediation and regeneration". J EsthetRestor Dent.2010 Feb; 22(1): 18-28.

[16]. Minsk L. "Clinical techniques in Periodontics: Esthetic crownlengthening". CompendcontinEduc Dent 2001; 22: 562

[17]. Oh SL. "Biologic width and crown lengthening: case reports and review". Gen Dent. 2010 SepOct; 58(5): 200-05.

[18]. Prichard J. Gingivoplasty. Gingivectomy and osseous surgery. Journal of Periodontology, Vol 32, Issue 4, pages 275-282.

[19]. American Academy of Periodontology. Glossary of Periodontol Terms, 4th ed. Chicago: American Academy of Periodontolgy; 2001;44.

[20]. Jacoby $H$. The etiology of maxillary canine $i m \neg$ paction. American Journal of Orthodontics 1983;84:125-132.

[21]. Bass T. Observation on the misplaced upper ca $\neg$ nine tooth. Dent Pract Dent Rec 1967;18:25-33.

[22]. Grover PS, Lorton L. The incidence of unerupted permanent teeth and related clinical cases. Oral Surg Oral Med Oral Pathol 1985;59:420-25.

[23]. Pietrokovski J, Massler M. Alveolar ridge resorption following tooth extraction. J Prosthet Dent 1967;17:21-27. 
[24]. Camargo PM, Lekovic V, Weinlaender M, et al. Influence of bioactive glass on changes in alveolar process dimensions after exodontia. Oral Surg Oral Med Oral Pathol Oral Radiol Endod 2000;90:581-586.

[25]. Fiorellini JP, Howell TH, Cochran D, et al. Randomized study evaluating recombinant human bone morphogenetic protein-2 for extraction socket augmentation. J Periodontol 2005;76:605-613.

[26]. Hillerup S. Preprosthetic surgery in the elderly. Journal of Prosthetic dentistry. November 1994, Volume 72, Issue 5, Pages 551-558

[27]. Cortellini P1, Tonetti MS. A minimally invasive surgical technique with an enamel matrix derivative in the regenerative treatment of intra-bony defects: a novel approach to limit morbidity. J Clin Periodontol. 2007 Jan;34(1):87-93.

[28]. Takei HH, Han TJ, Carranza FA Jr, Kenney EB, Lekovic V. Flap technique for periodontal bone implants. Papilla preservation technique. J Periodontol 1985;56:204 10.

[29]. Cortellini P, Prato GP, Tonetti MS. The modified papilla preservation technique. A new surgical approach for interproximal regenerative procedures. J Periodontol 1995;66:261 6.

[30]. Bianchi AE, Bassetti A. Flap design for guided tissue regeneration surgery in the esthetic zone: The "Whale's tail" technique. Int J Periodontics Restorative Dent 2009;29:153 9.

[31]. Trombelli L, Farina R, Franceschetti G. Utilizzo del Single Flap Approach in Chirurgia Parodontale Ricostruttiva. Dent Cadmos 2007;8:15-25.

[32]. Trombelli L, Farina R, Franceschetti G, Calura G. Single-flap approach with buccal access in periodontal reconstructive procedures. J Periodontol 2009;80: 353-360.
[33]. Tibbetts L. Principles and practice of periodontal micvrosurgery. Int J Microdent 2009;1:13-24.

\section{Cite this article as :}

Dr. Grishmi Niswad, Dr. Salman Ansari, 'Aesthetics in Periodontal Therapy!', International Journal of Scientific Research in Science and Technology(IJSRST), Print ISSN : 2395-6011, Online ISSN : 2395-602X,Volume 4 Issue 11, pp.272-277, November-December 2018. Available at doi : https://doi.org/10.32628/IJSRST18401154 Journal URL : http://ijsrst.com/IJSRST18401154 